\title{
AYUDAS FOTOGRÁFICAS Y COMPUTARIZACIÓN DE IMÁGENES DE MANUSCRITOS DE DIFÍCIL LECTURA
}

Prácticamente todo lector de manuscritos tropieza en algún momento con el problema de descifrar un texto que ha sido tachado, bien por el autor original o durante algún proceso de revisión por parte del consiguiente editor o censor. El manuscrito autógrafo de la primera parte de la trilogía dramática de Tirso de Molina, La Santa Juana, plantea este problema de forma particularmente interesante pues las partes tachadas que presenta aportan una evidencia inusual del proceso de censura en el ámbito del mundo teatral del Siglo de Oro español. Con la ayuda de capacidades fotográficas modernas y las técnicas gráficas computarizadas, hemos logrado leer el texto tachado en el manuscrito de Tirso. El propósito de este artículo es el de describir el procedimiento que hemos seguido y los frutos que ha rendido; quisiéramos comunicar esta información a un amplio público de investigadores, y en particular a los que no son expertos en el uso de los computadores, con la esperanza de que otros puedan obtener los mismos beneficios.

El manuscrito de Tirso, firmado y fechado en Toledo en 1614, que se encuentra en la Biblioteca Nacional de Madrid con número de catálogo MS Res. 249, contiene las tres partes de la trilogía, la primera y tercera de las cuales son autógrafas y la segunda de mano de un copista. La primera y segunda parte fueron publicadas en versiones significativamente diferentes en la Quinta Parte de las Comedias de Tirso (Madrid, 1636). Ambas versiones de la primera parte parecen venir de la pluma de Tirso. Greer cree que el manuscrito es el resultado de una revisión hecha por el propio Tirso, basándose en su versión más larga publicada en 1636, con el objeto de producir un texto más corto, más melodramático y menos cortesano, destinado a una gira provincial de la obra ${ }^{1}$.

\footnotetext{
${ }^{1}$ Para la comparación de las versiones, ver Greer, " "Authority" in Co-
} 
La trilogía pone en escena la vida de una monja de la Sagra de Toledo, Juana de la Cruz, que alcanzó en la imaginación popular rango de leyenda y de santidad ya en tiempos de Tirso, aunque no sería tan altamente considerada por las propias jerarquías eclesiásticas. Aunque Tirso mismo fue un clérigo, esto no impediría que un censor eclesiástico realizara purgas sustanciales a la primera parte del manuscrito, especificando que en el título y en toda referencia a Juana en la obra habría de figurar como "Sor Juana" y no "Santa Juana". A su vez elimina o revisa algunos pasajes en los cuales Tirso pone de manifiesto una actitud no tan reverente hacia figuras e instituciones religiosas, al retratar, por ejemplo, a una monja como amargamente envidiosa y enfrentada a la propia Juana, y al comparar una taberna con una ermita. En los márgenes junto a los pasajes cancelados, el censor escribió extensos comentarios poniendo de relieve sus objeciones. El censor mismo sería a su vez censurado por una mano posterior, probablemente la del dueño de la compañía teatral, que tacharía los comentarios del censor con una tinta de diferente color de la del censor, y escribiría "dicese" al margen de los mismos, por encima o por debajo de los comentarios tachados del censor.

Hace casi un siglo, A. Paz y Meliá2 consiguió descifrar el comentario del censor que figura en la primera página del manuscrito. La tinta que pretende tachar el texto no es muy densa en esta página, y pudimos confirmar su lectura, aunque habríamos tenido dificultad en leerla independientemente, bien por la persistencia en la imbricación de ambos colores de las tintas a lo largo del tiempo, o por menores habilidades paleográficas. Paz y Meliá no abordó los comentarios del censor de otras páginas. Varias de éstas estaban mucho más tachadas y ni Greer, que está trabajando sobre la edición doble de las obras, ni Manuel Sánchez Mariana, Jefe de la Sección de Raros de la Biblioteca Nacional de Madrid, ni otros investigadores fueron capaces de reconstruir más que palabras aisladas.

Sometidos a esta frustración, decidimos poner a prueba las capacidades fotográficas modernas y las técnicas gráficas computarizadas para intentar desvelar los textos ocultos. Nuestra decisión estuvo inspirada por una conversación entre Greer y Kurtz sobre

media editions: Tirso de Molina's Santa Juana', en Frank Casa y Michaer McGaHA, Editing the Comedia, Michigan Romance Studies, 1991, t. 2.

${ }^{2}$ Catálogo de las piezas de teatro que se conservan en el Departamento de Manuscritos de la Biblioteca Nacional, Imprenta del Colegio Nacional de Sordomudos y Ciegos, Madrid, 1899. 
las experiencias de este último en la fotografía de textos pintados en la Cueva Negra en Fortuna (Murcia), correspondientes a la época romana. Con la aplicación de técnicas fotográficas sofisticadas, letras que de otra forma habrían sido "invisibles" consiguieron ser leídas ${ }^{3}$. Una segunda fuente de inspiración serían los informes sobre los avances conseguidos en la lectura de los manuscritos del Mar Muerto con la aplicación de técnicas de refuerzo del color con sistemas computarizados.

Al haber una diferencia perceptible entre las tintas utilizadas por el censor y la utilizada por el tachador, pensamos que también diferirían en su absorción de fuentes de "luz" de longitud de onda pertenecientes a regiones próximas a la de la luz visible, lo cual permitiría obtener una diferenciación más notable entre las dos tintas que facilitaría la lectura del texto tachado del censor. Kurtz experimentó con infrarrojos y ultravioletas, y además se aplicó un sistema particular que involucra la manipulación de luz polarizada. De estas experiencias se derivan los resultados siguientes.

\section{Luz infrarroja reflejada.}

Película: Kodak High Speed Infrared.

Fuente de iluminación: Flash Metz 45 CT1.

Filtro: Wratten $\mathrm{N}^{\circ} 87$.

Los resultados obtenidos, aun no siendo espectaculares, indican que la tinta utilizada por el tachador refleja más infrarrojos que la utilizada por el censor. Se consigue por este procedimiento una imagen con una ligera diferenciación entre las dos tintas pero no lo suficientemente marcada como para ser apreciada en la copia fotográfica. El negativo producido por este procedimiento, observado directamente en proyección, permite apreciar una mayor diferencia entre las tintas que la observable en el correspondiente positivo. Por ello es razonable pensar que la lectura digital de este negativo proporcionaría información útil para la lectura del texto.

Basándonos en esta evidencia, asumimos que el uso de la película infrarroja de falsos colores daría buenos resultados de registrarse la diferencia entre las dos tintas. Kurtz realizó las prue-

3 "La Cueva Negra de Fortuna (Murcia) y sus Tituli Picti, un santuario de época romana", en Monografias históricas sobre la antigüedad tardía, t. 4: Antigüedad y Cristianismo, Universidad de Murcia, 1987. 
bas con la película Kodak Ektachrome Infrared, la única disponible comercialmente hoy en día. Desgraciadamente esta película requiere del proceso $\mathrm{E} 4$ para su correcto revelado y éste ha sido abandonado a favor del E6, proceso para el cual no existe película infrarroja de falsos colores comercializada. La película con la que se realizaron las pruebas fue enviada para ser procesada a un centro hospitalario de Madrid que para aplicaciones médicas sí procesa con un proceso parecido al E4. Los resultados no fueron satisfactorios y no podemos por tanto evaluar la utilidad de la aplicación de esta película para la lectura de manuscritos.

\section{Luminiscencia infrarroja.}

Película: Kodak High Speed Infrared.

Fuente de iluminación: Luz tungsteno filtrada a través de filtro verde-azul Corning $\mathrm{N}^{\circ} 9780$.

Filtro: Wratten $N^{\circ} 87$.

Si bien los resultados no fueron concluyentes (debido fundamentalmente a lo delicado de esta técnica que requiere de un control de la iluminación mayor del que se pudo ejercer en el cuarto de que dispusimos en la Biblioteca Nacional para la realización de las pruebas), pudo apreciarse que ninguna de las dos tintas presentaban marcados fenómenos de luminiscencia que permitieran diferenciarlas. El fenómeno de la luminiscencia infrarroja consiste en la "aparición" de una "emisión" infrarroja por un sujeto que recibe únicamente luz de longitudes de onda más pequeñas que las del infrarrojo. En el caso que nos ocupa, el manuscrito recibió una luz verde-azul.

\section{Ultravioleta reflejado.}

Película: Kodak Plus X.

Fuente de iluminación: Flash Metz 45 CT1.

Filtro: $\mathrm{B}+\mathrm{W} \mathrm{N}^{\circ} 430$.

La aplicación de esta técnica no dio resultados positivos en la separación de las tintas. La absorción de luz ultravioleta por ambas tintas fue muy alta y por consiguiente se obtuvo una imagen con las dos tintas completamente fundidas entre sí. No obstante, en casos donde se requiera resaltar una tinta, como en casos de manuscritos borrados o de letras muy tenues, esta técnica puede resultar muy útil. 


\section{Polarización inducida o cruzada.}

Película: Transparencia de color.

Esta técnica fue la que en definitiva produjo un registro fotográfico que facilitó la lectura del texto del censor. El procedimiento consiste en fotografiar un solo plano de vibración de la luz para obtener una imagen de máxima saturación y pureza de color. Debido a un pequeño defecto en el cálculo de la exposición efectua$\mathrm{da}$, las tomas resultaron claramente sobreexpuestas. Esto proporcionó una imagen en la que se aprecia con claridad una diferenciación entre ambas tintas. La tinta del texto del censor escondida por la del tachador es lógicamente la parte de la imagen que tiene más densidad al combinarse allí dos tintas. Estos puntos de contacto entre las dos tintas son las zonas más oscuras y por ello requerirán de una exposición mayor antes de ser "lavadas" por sobreexposición. El resultado concreto que se obtuvo en la diferenciación de las tintas que nos ocupa consiste en transparencias en las que las tachaduras han sido suficientemente aclaradas (casi hasta "lavarse" del todo) poniéndose de relieve la imagen de la tinta que ocultaban.

El procedimiento es el siguiente:

El manuscrito es iluminado de forma convencional para su reproducción, pero con un filtro polarizador sobre cada fuente de iluminación. Ha de observarse meticulosamente que estos polarizadores estén colocados con sus ejes de polarización en idéntica dirección. En el objetivo de la cámara se coloca otro filtro polarizador, esta vez con el eje de polarización a $90^{\circ}$ respecto al eje de los polarizadores situados en las fuentes de iluminación.

En el cálculo de la exposición han de considerarse las pérdidas de luz producidas por la absorción de luz efectuada por los polarizadores. Se "perderán" seis diafragmas, dos en la iluminación misma, otros dos se pierden en el polarizador situado en el objetivo y dos más se pierden por la extinción de luz producida por el cruce entre los ejes de polarización del objetivo y los de la iluminación.

Se realizarán pruebas de exposición para determinar con exactitud el grado de sobreexposición deseada y que asegura un máximo de sobreexposición para "lavar" la tinta tachadora con un mínimo de pérdida de información en las tintas tachadas. Este punto puede ser crítico pero con la sobreexposición obtenida con el equivalente a la apertura de uno o dos diafragmas por encima de la exposición correcta se alcanzará la sobreexposición deseada. 
En el caso concreto del manuscrito de Tirso, este procedimiento proporcionó transparencias que reprodujeron la tinta del tachador en un color ámbar al que es muy poco sensible el papel fotográfico de blanco y negro. Efectivamente al positivar ("negativar" en este caso) las transparencias en este tipo de papel, Kurtz produjo imágenes negativas del texto que facilitaban la lectura de los textos ocultos por las tachaduras. Las partes más ligeramente tachadas, tales como las leídas por Paz y Meliá, pudieron ser así leídas sin dificultad alguna. En los segmentos más densamente tachados, la mejora de la legibilidad fue mucho menos espectacular; para descifrar el texto escondido en las partes más difíciles se requiere aún de un análisis visual tan detallado como el necesario para la lectura de cualquier manuscrito difícil. Sea como fuera, con la asistencia de la erudición paleográfica de Jaime Moll y con la repetida comparación entre las transparencias de color y las imágenes negativas en blanco y negro, hemos podido leer a satisfacción todos los comentarios tachados.

Aunque esto satisfizo los objetivos iniciales de Greer al acometer el proyecto, decidimos continuar con éste realizando pruebas de digitalización computarizada de las imágenes de los textos en estudio. La intención al abordar estas pruebas es demostrar la utilidad potencial de las capacidades del análisis digital de la imagen en trabajos de lectura de manuscritos similares al que aquí se estudia. Esta parte del trabajo se realizó en el Interactive Computer Graphics Laboratory de la Universidad de Princeton, por el encargado-jefe de este laboratorio, Kirk Alexander, con la asistencia de Brad Gianulis. Con fines comparativos trabajamos con una muestra de los textos más legibles por un lado, aquel leído por Paz y Meliá, y por otro con una muestra de los textos más difíciles. Utilizando las transparencias de color obtenidas con luz polarizada, se pasaron por el scanner tanto la imagen normal como la sobreexpuesta. Se realizó esta digitalización con un scanner Howtek Scanmaster de lectura plana. Las imágenes fueron procesadas con un IBM AT, utilizando el Decision Images como software, un programa originalmente diseñado para reforzar imágenes fotográficas obtenidas por satélite. Se experimentó con las imágenes en dos tipos de monitores diferentes; la más satisfactoria de las dos fue la Silicon Graphics IRIS 40/20 Workstation que permite poner seis o más imágenes a la vez en pantalla. Además permite superponer las imágenes y realizar una variedad de manipulaciones de utilidad a la vez que se superponen.

El objetivo teórico consistía en acentuar la diferenciación en- 
tre las dos tintas de tal manera que se pudiera "levantar" la tinta tachadora. En la primera serie de pruebas seleccionamos " manualmente" segmentos de la imagen que claramente pertenecían a una $u$ otra tinta y trabajando con sus contenidos de los tres colores fundamentales, rojo, verde o azul, de cada una de las lecturas digitales se ordenó al programa detectar e intensificar la combinación particular de color de cada una de las tintas que encontrara en la imagen. Esto sería sólo parcialmente útil al no ser suficientemente distintas ambas tintas en cuanto a sus diferencias de color. Al eliminar uno de los registros de color de una de las tintas (la del tachador) a base de convertirlo en un tercer color, se eliminaba a la vez la imagen de la tinta del texto debido a la similitud de combinación de colores entre ambas tintas. De todas formas sí se obtuvo alguna mejora, pero no lo suficientemente significativa como para permitir la lectura de la imagen más difícil.

Se realizó a continuación un análisis estadístico con la información digitalizada con el propósito de encontrar los colores más frecuentes y averiguar si alguno de ellos coincidía consistentemente con el de la tinta tachadora. Se estableció un rango de veinte colores, aunque es posible que hubiera resultado más adecuado realizarlo con menor cantidad de colores. La computadora tardó cerca de dos horas en realizar el análisis. Los resultados de éste fueron, una vez más, algo decepcionantes. Es seguro de todas formas que este análisis produciría buenos resultados en casos en que la diferencia entre colores de tintas fuera más marcada.

El análisis fue entonces repetido pero esta vez fraccionando el componente del color en tres factores distintos: tono, intensidad y saturación. Este proceso de análisis sí proporcionó resultados espectaculares. En efecto, el análisis de la imagen por grados de saturación proporcionó imágenes de las mismas características que las obtenidas con el "negativado" sobre papel fotográfico de blanco y negro de la transparencia de color expuesta que se ha descrito. Como el programa utilizado permite un control dinámico del contraste de la imagen por medio de los movimientos de un "ratón", pudimos manipular el grado de "sobreexposición', variando el grado de saturación. Esta posibilidad es de gran utilidad pues la tinta tachadora es de densidad variable según el segmento de texto que afecte. Allí donde la imagen fotográfica ha de hacer un compromiso de exposición para la generalidad de la imagen, la manipulación de la imagen en el monitor permite variar la saturación del color por segmento, aclarando y oscureciendo a voluntad, permitiéndose así la máxima legibilidad 
en cada palabra o letra. De este modo fue posible hacer casi desaparecer la tinta tachadora en el texto más fácil. Para el texto más difícil se superpusieron en pantalla otras imágenes derivadas del análisis del tono y de la intensidad, resultando así claramente legible este texto.

Nuestra conclusión es que ambas técnicas, tanto fotográfica como computarizada, pueden ser herramientas de gran utilidad para la lectura de manuscritos problemáticos. En algunos casos la clarificación fotográfica será más que suficiente. Al no ser todavía posible conjuntar un scanner de alta calidad con el manuscrito original, el análisis y la aplicación de los procedimientos digitales seguirá dependiendo de la obtención de reproducciones fotográficas de calidad.

El procedimiento ideal sería el de trabajar desde el principio con imágenes digitalizadas del texto que se quiere leer. Al utilizar una cámara de televisión para "fotografiar" el texto, y así poder mantener un enfoque constante, se podrían combinar todas las técnicas fotográficas que Kurtz empleó en secuencia, lo cual sería mucho más eficaz para revelar el texto subyacente que su aplicación sucesiva y separada. Esto permitiría la aplicación directa e instantánea de técnicas de intensificación computarizadas a esta imagen digitalizada sin la intervención del scanner. Además, nuevos avances tecnológicos tales como las cámaras CCD y hardware que efectúan conversiones instantáneas de tono, intensidad y saturación, prometen aumentar la viabilidad de este procedimiento.

Una nota final de Greer: nuestro éxito en la lectura de este manuscrito, aun dependiendo de las posibilidades técnicas de la fotografía y de la computarización, requirió tanto de un alto grado de arte como de ciencia. La aplicación mecánica de estas técnicas no hubiera producido los resultados obtenidos sin la combinación de interés, habilidad e inteligencia vertidos en el problema por Kurtz en la parte fotográfica y por Alexander en el análisis computarizado. Fotógrafos e informáticos de menor experiencia serán capaces de aprender estas técnicas, pero este éxito inicial no hubiera sido posible sin su talento.

Margaret Rich Greer Princeton University 